\title{
NUMERICAL INVESTIGATION OF THE ELASTIC-PLASTIC LINEAR HARDENING STRESS-STRAIN STATE OF THE FRAME ELEMENT CROSS-SECTION
}

\author{
Andrius GRIGUSEVIČIUS, Gediminas BLAŽEVIČIUS \\ Department of Structural Mechanics, Faculty of Civil Engineering, Vilnius Gediminas Technical Univer- \\ sity, Sauletekio al. 11, LT-10223 Vilnius, Lithuania
}

Received 13 June 2016; accepted 25 July 2016

\begin{abstract}
The aim of this paper is to present a solution algorithm for determining the frame element crosssection carrying capacity, defined by combined effect of bending moment and axial force. The distributions of stresses and strains inside a cross-section made of linearly hardening material are analysed. General nonlinear stress-strain dependencies are composed. All relations are formed for rectangular cross-section for all possible cases of combinations of axial force and bending moment. To this end, five different stress-strain states are investigated and four limit axial force values are defined in the present research. The nonlinear problem is solved in MATLAB mathematical software environment. Stress-strain states in the cross-sections are investigated in detail and graphically analysed for two numerical experiments.
\end{abstract}

Keywords: linear hardening, rectangular cross-section, combined effect of bending moment and axial force, stress-strain state, MATLAB implementation.

\section{Introduction}

Several material models can be used for evaluation of plastic strains in the structural elements: perfectly rigid-plastic, perfectly elastic-plastic, linearly hardened (Čyras et al. 2004; Kalanta 2007; Jaras, Kačianauskas 2001, 2002; Davies 2002). As it is investigated by experiments (Sawko 1964; Byfield et al. 2005), the last model has the best correspondence to the real steel stress-strain dependency in the structure.

The effect of linear hardening and general nonlinear material models of stress-strain state of cross-sections are analysed in many papers (Atkočiūnas, Čižas 2009; Dulinskas et al. 2010; Van Long, Dang Hung 2008a, 2008b). Some of them are related to the pure bending only, in other ones an effect of axial forces is evaluated, though only for very simple - perfectly elastic-plastic material model. Straightening of nonlinear stress distribution in cross-sections using equivalent or averaged rectangular stress blocks is suggested in paper (Dulinskas et al. 2010).

In most of the literature related to physically non-linear beam structures, simplified approaches for evaluation of cross-section plasticity are investigated. Most common are: plastic hinge approach (Landesmann 2010; Kalanta 2007) and semi-rigid connection approach (Hu, Zhou 2012; Sekulovic, NefovskaDanilovic 2008). The techniques of such approaches have significant computation advantage, but analysis in most cases is suitable for preliminary approximate study as it is unable to deal with the spread of material plasticity.

The main aim of this paper is to create and apply a methodology for an exact determination of elastic and plastic zones in a cross-section, when linear hardening material model and combined effect of axial force and bending moment are evaluated. To achieve this goal,

Corresponding author:

A. Grigusevičius E-mail: andrius.grigusevicius@vgtu.lt 
several systems of nonlinear equations must be created and solved, however solutions of these equations are complicated and still not analysed well enough (Juriev 1977; Webster, Ellison 1967). Mathematical software MATLAB (Moore 2014) was used to overcome some of these difficulties in the present paper. Programming code was created for solving such problems, i.e. performing numerical and graphical analysis of stressstrain state of a rectangular cross-section.

\section{Main equations of stress-strain state}

Equilibrium of forces and bending moments must be valid in any cross-section subjected to bending moment $M$ and axial force $N$ :

$$
N=\int_{A} \sigma(y) d A ; M=\int_{A} y \sigma(y) d A,
$$

where $A$ is area of the cross-section; $y$ - distance to neutral axis of the cross-section; $\sigma$ - normal stress.

Linearly hardening material model is described by stress-strain diagram (Fig. 1) composed of two deformation stages - elastic and elastic-plastic. Normal stresses $\sigma$ and longitudinal strains $\varepsilon$ in this diagram are related by such equations:

$$
E=\sigma_{0} / \varepsilon_{0} ; E_{h}=\left(\sigma-\sigma_{0}\right) /\left(\varepsilon-\varepsilon_{0}\right),
$$

where $E$ and $E_{h}$ are elastic and hardening modules; $\sigma_{0}$ and $\varepsilon_{0}$ - limit elastic stress and strain of the material.

Elastic-plastic stage (when $\sigma>\sigma_{0}$ ) can be expressed by hardening ratio $\alpha=E_{h} / E$ :

$$
\sigma=\sigma_{0}+\alpha E\left(\varepsilon-\varepsilon_{0}\right) \text {. }
$$

Since hypothesis of plane sections must be satisfied, following relation have to be valid:

$$
\kappa=-\frac{\varepsilon_{\max }-\varepsilon_{\min }}{h},
$$

where $\kappa$ is curvature; $\varepsilon_{\max }, \varepsilon_{\min }$ - longitudinal strains at the top and bottom of the cross-section; $h$ - crosssection height.

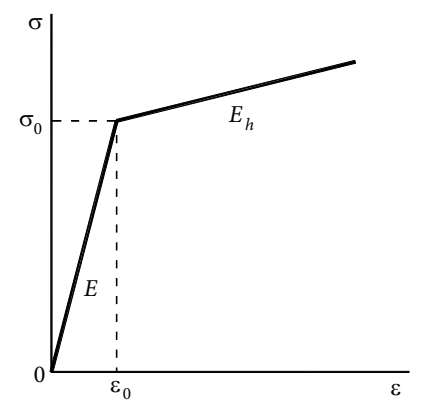

Fig. 1. Stress-strain diagram of linearly hardening material model

\subsection{Pure bending}

In this case axial force is zero $-N=0$, therefore formation of the force equilibrium is unnecessary. Equilibrium of bending moments can be written as equality between moment $M$ and internal moment generated by normal stresses in respect of neutral line of a rectangular cross-section (Fig. 2):

$$
\begin{gathered}
M=\frac{b h_{e l}^{2}}{6} \sigma_{0}+0.25 b\left(h-h_{e l}\right)\left(h+h_{e l}\right) \sigma_{0}+ \\
\frac{1}{12} b\left(h-h_{e l}\right)\left(2 h+h_{e l}\right)\left(\sigma_{\max }-\sigma_{0}\right),
\end{gathered}
$$

where $b$ is width of the section.

First term of Equation (5) corresponds to the internal moment generated by stresses of an elastic core $h_{e l}$; second and third terms correspond to the moments generated by stresses in elastic-plastic zones $0.5 h_{p l}$ (Fig. 2).

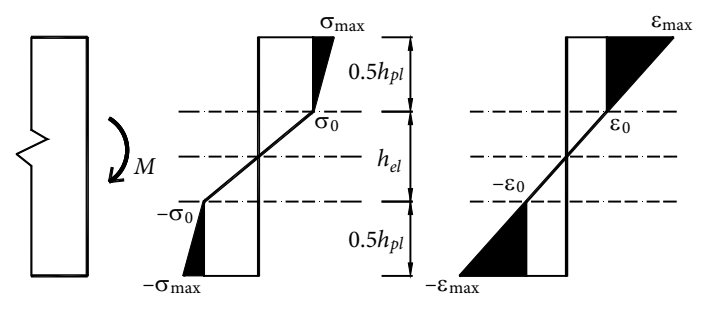

Fig. 2. Distributions of stresses and strains in the cross-section in case of pure bending

For a rectangular cross-section, relations satisfying plane sections hypothesis are:

$$
\varepsilon_{\max }=-\kappa \frac{h}{2} ; \kappa=-\frac{2 \sigma_{0}}{E h_{e l}} .
$$

Nonlinear system of four equations (3), (5) and (6) can be expressed by any of the four unknowns $\varepsilon_{\max }, \kappa, h_{e l}$ or $\sigma_{\max }$. For instance, expression of longitudinal strain $\varepsilon_{\max }$ is obtained as follows:

$$
\bar{a} \varepsilon_{\text {max }}^{3}-\bar{b} \varepsilon_{\text {max }}^{2}-\bar{c}=0,
$$

where $\bar{a}=2 \alpha E^{3} W ; \bar{b}=E^{2}\left(2 M-3 W \sigma_{0}(1-\alpha)\right)$; $\bar{c}=W \sigma_{0}^{3}(1-\alpha)$ and $W$ is a resistance moment of rectangular cross-section.

If bending moment sign is taken to be positive, the only positive root of the cubic Equation (7) defines true maximum strain of the cross-section $\varepsilon_{\max }$.

\subsection{Combined effect of bending moment and axial force}

Five cases of bending moment and axial force equilibrium must be analysed for definition of five different stress-strain states in the cross-section. Four limit values of axial force restrict these states. In this paper, 
all five cases are analysed assuming that bending moment and axial force are positive (positive directions are shown in Fig. 3). For these positive directions, the curvature $\kappa$ and the coordinate of neutral line $y_{0}$ will always have negative values:

1. First case. If $M<M_{0}$ and $N \leq N_{\text {lim1 }}$ (only elastic strains in the cross-section),

where $M_{0}$ is limiting bending moment of the crosssection (it corresponds to the elastic stress limit); $N_{\lim 1}$ is the first axial force limit. This limit defines maximum axial force which, together with acting bending moment, develops only the elastic strains in the cross-section. For a rectangular cross-section these values are:

$$
M_{0}=\sigma_{0} \frac{b h^{2}}{6} ; N_{\lim 1}=\frac{6\left(M_{0}-M\right)}{h} .
$$

Plastic strains are not developing in this case, therefore normal stresses and longitudinal strains are calculated by well-known equations of elastic state:

$$
\begin{aligned}
\sigma_{\max } & =\frac{M}{W}+\frac{N}{A} ; \sigma_{\min }=-\frac{M}{W}+\frac{N}{A} ; \varepsilon_{\max }=\frac{\sigma_{\max }}{E} ; \\
\varepsilon_{\min } & =\frac{\sigma_{\min }}{E} .
\end{aligned}
$$

2. Second case. If $N \leq N_{\lim 2}$ and $\sigma_{\max } \geq \sigma_{0}$ (Fig. 3a), where $N_{\lim 2}$ is second axial force limit. This limit defines axial force which, together with acting bending moment, develops normal stress $\sigma_{\min }=-\sigma_{0}$ (Fig. 4b). Second axial force limit can be expressed using equilibrium Eq. (1) and the equations of plane section hypothesis:

$$
N_{\lim 2}=\sigma_{0} b\left(h-h_{e l}+\alpha\left(\frac{h^{2}}{h_{e l}}-2 h+h_{e l}\right)\right),
$$

a)
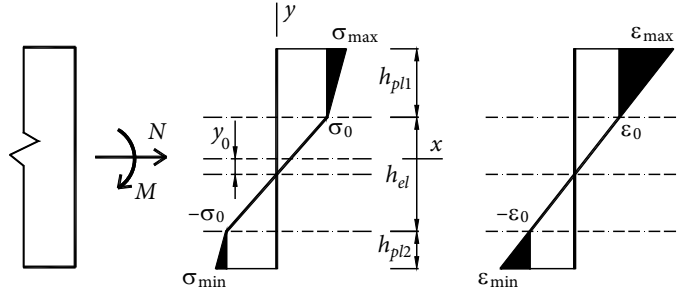

b)
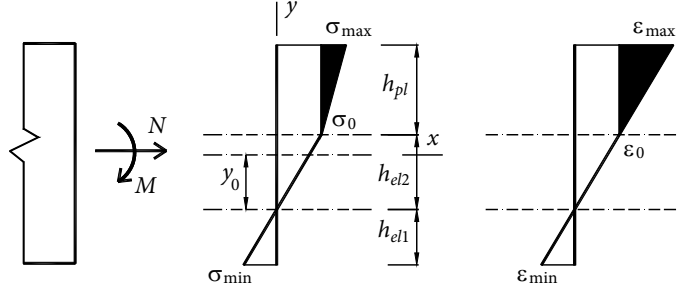

Fig. 3. Distributions of stress and strains in the cross-section resulted by combined effect of axial force and bending moment: (a) second case of equilibrium; (b) third case of equilibrium and the elastic core $h_{e l}$ is calculated from the cubic equation:

$$
\bar{a} h_{e l}^{3}+\bar{b} h_{e l}^{2}+\bar{c} h_{e l}-\bar{d}=0,
$$

where $\bar{a}=2 \sigma_{0} b(1-\alpha) ; \bar{b}=3 \sigma_{0} b h(\alpha-1) ; \bar{c}=6 M$;

$\bar{d}=\alpha \sigma_{0} b h^{3}$.

Values of stress-strain state when $\sigma_{\min } \leq-\sigma_{0}$ (Fig. 3a) are calculated as follows. At first, the coordinate of neutral line $y_{0}$ is calculated from fifth order non-linear equation:

$$
\bar{a} y_{0}^{5}+\bar{b} y_{0}^{4}+\bar{c} y_{0}^{3}+\bar{d} y_{0}^{2}+\bar{e} y_{0}+\bar{f}=0,
$$

where $\bar{a}=48 \sigma_{0}^{3} b^{3}\left(3 \alpha^{2}-3 \alpha-\alpha^{3}+1\right)$;

$\bar{b}=48 N \sigma_{0}^{2} b^{2}\left(\alpha^{2}-2 \alpha+1\right)$;

$\bar{e}=3 N^{2}\left(4 M+\sigma_{0} b h^{2}(1-\alpha)\right) ; \bar{f}=N^{3} h^{2} ;$

$\bar{c}=4 \sigma_{0} b\left(12 M \sigma_{0} b\left(\alpha^{2}-2 \alpha+1\right)+3 N^{2}(1-\alpha)+\right.$

$\left.\sigma_{0}^{2} b^{2} h^{2}\left(3 \alpha-2 \alpha^{2}-1\right)\right)$

$\bar{d}=48 M N \sigma_{0} b(1-\alpha)$.

Hereafter, elastic core is calculated from the cubic equation:

$$
\bar{a} h_{e l}^{3}+\bar{b} h_{e l}+\bar{c}=0,
$$

where $\bar{a}=12 \sigma_{0} b(\alpha-1)$;

$\bar{b}=0.25 \sigma_{0} b(1-\alpha)\left(h^{2}+4 y_{0}^{2}\right)-M+N y_{0} ;$

$\bar{c}=\alpha \sigma_{0} b h\left(2 y_{0}^{2}+h^{2} / 6\right)$.

Other unknowns in this state are calculated as follows:

$$
\begin{gathered}
\kappa=-\frac{2 \sigma_{0}}{h_{e l} E} ; \\
\varepsilon_{\max }=-\kappa\left(0.5 h-y_{0}\right) ; \\
\varepsilon_{\min }=\kappa\left(0.5 h+y_{0}\right) ; \\
\sigma_{\max }=\sigma_{0}(1-\alpha)+E_{h} \varepsilon_{\max } ; \\
\sigma_{\min }=-\sigma_{0}(1-\alpha)+E_{h} \varepsilon_{\min } .
\end{gathered}
$$

3. Third case. If $N \leq N_{\lim 3}$ and $-\sigma_{0} \leq \sigma_{\min } \leq 0$ (Fig. 3b), where $N_{\text {lim3 }}$ is third axial force limit. This limit defines axial force which, together with acting bending moment, develops zero normal stress $\sigma_{\text {min }}=0$ (Fig. $4 \mathrm{~b}$ ):

$$
N_{\lim 3}=\sigma_{0} b\left(h-0.5 h_{e l}+\alpha\left(\frac{h^{2}}{2 h_{e l}}-h+0.5 h_{e l}\right)\right) \text {. }
$$

The elastic core $h_{e l}$ is calculated from the cubic equation:

$$
\bar{a} h_{e l}^{3}+\bar{b} h_{e l}^{2}+\bar{c} h_{e l}-\bar{d}=0,
$$

where $\bar{a}=\sigma_{0} b(1-\alpha) ; \quad \bar{b}=1.5 \sigma_{0} b h(\alpha-1) ; \quad \bar{c}=6 M$; $\bar{d}=0.5 \alpha \sigma_{0} b h^{3}$. The values of stress-strain state when $-\sigma_{0} \leq \sigma_{\min } \leq 0$ and $\sigma_{\max } \geq \sigma_{0}$ (Fig. $3 \mathrm{~b}$ ) are calculated by solving the nonlinear system of seven equations: 


$$
\begin{gathered}
0.5 b h_{e l 1} \sigma_{\min }+0.5 b \sigma_{0} h_{e l 2}+b \sigma_{0} h_{p l}+ \\
0.5 b\left(\sigma_{\max }-\sigma_{0}\right) h_{p l}=N ; \\
-\frac{1}{3} b \sigma_{\min } h_{e l 1}^{2}+\frac{1}{3} b \sigma_{0} h_{e l 2}^{2}+b \sigma_{0} h_{p l}\left(0.5 h_{p l}+h_{e l 2}\right)+ \\
0.5 b\left(\sigma_{\max }-\sigma_{0}\right) h_{p l}\left(\frac{2}{3} h_{p l}+h_{e l 2}\right)=M-N y_{0} ; \\
\sigma_{0}-\alpha \sigma_{0}+E_{h} \kappa\left(y_{0}-0.5 h\right)=\sigma_{\max } ; \\
E \kappa\left(y_{0}+0.5 h\right)=\sigma_{\min } ;-E \kappa h_{e l 2}=\sigma_{0} ; \\
y_{0}+0.5 h=h_{e l 1} ; 0.5 h-y_{0}-h_{e l 2}=h_{p l}
\end{gathered}
$$

Equation (19) describes equilibrium of forces in the direction perpendicular to the cross-section plane; equation (20) is the equilibrium of bending moments in respect to neutral axis; equations (21) relates stresses and curvature in various zones of the cross-section height (according to the hypothesis of plane sections); equations (22) relates geometrical parameters of the cross-section height (Fig. 3b).

4. Fourth case. If $N_{\lim 3}<N<N_{\lim 4}$ and $0 \leq \sigma_{\min } \leq \sigma_{0}$ (Fig. 4d),

where $N_{\lim 4}$ is fourth axial force limit. This limit defines axial force which, together with acting bending moment, develops normal stress $\sigma_{\min }=\sigma_{0}$ (Fig. 4c):

$$
N_{\lim 4}=\sigma_{0} b h+\frac{6 M}{h} \text {. }
$$

Characteristics of stress-strain state, when $0 \leq$ $\sigma_{\min } \leq \sigma_{0}$ and $\sigma_{\max } \geq \sigma_{0}$ (Fig. $4 \mathrm{~d}$ ) are calculated as follows. At first, elastic core $h_{e l}$ is calculated from cubic equation:

$$
\bar{a} h_{e l}^{3}+\bar{b} h_{e l}^{2}-\bar{c} h_{e l}+\bar{d}=0,
$$

where $\bar{a}=\frac{1}{6} b\left(E-E_{h}\right)\left(N-\sigma_{0} b h\right)$;

$\bar{b}=0.25 b\left(E-E_{h}\right)\left(6 \sigma_{0} W-2 M-N h\right) ;$

$\bar{d}=E_{h} W\left(3 \sigma_{0} W-0.5 N h+3 M\right)$;

$\bar{c}=M E_{h} b h$.

Hereafter, curvature is calculated from quadratic equation:

$$
\bar{a} \kappa^{2}+\bar{b} \kappa+\bar{c}=0,
$$

where

$$
\begin{aligned}
& \bar{b}=E\left(\sigma_{0} b\left(\frac{h^{2}}{2}(1+\alpha)-\frac{h_{e l}^{2}}{2}(1-\alpha)-h h_{e l}(1+\alpha)\right)-\right. \\
& \left.M+N h_{e l}-\frac{1}{2} N h\right) ; \\
& \bar{c}=\sigma_{0}\left(N-\sigma_{0} b h\right) ; \\
& \bar{a}=E b\left(E_{h} h_{e l}\left(h^{2}-h h_{e l}+h_{e l}^{2} / 3\right)-1 / 3\left(E_{h} b^{3}+E h_{e l}^{3}\right)\right) .
\end{aligned}
$$

Other unknowns of this state are calculated as follows:

$$
\begin{gathered}
\sigma_{\max }=\sigma_{0}-E_{h} \kappa\left(h-h_{e l}\right) ; \sigma_{\min }=\sigma_{0}+E_{h} \kappa h_{e l} ; \\
\varepsilon_{\max }=\frac{\sigma_{0}}{E}+\frac{\sigma_{\max }-\sigma_{0}}{E_{h}} ; \varepsilon_{\min }=\frac{\sigma_{\min }}{E} ; \\
y_{0}=\frac{\sigma_{0}}{E \kappa}+h_{e l}-0.5 h .
\end{gathered}
$$

5. Fifth case. If $N \geq N_{\lim 4}$ (Fig 4 e). In this case, plastic strains are developing in the entire area of the cross-section and therefore $h_{e l}=0, h_{p l}=h$. Other unknowns are calculated as follows:

$$
\begin{gathered}
y_{0}=\frac{\sigma_{0} b h^{3}(1-1.5 \alpha-h N h+3 M}{18 M} ; \\
\kappa=-\frac{12 M}{E_{h} b h^{3}} ; \\
\varepsilon_{\max }=\kappa\left(y_{0}-0.5 h ; \varepsilon_{\min }=\kappa\left(y_{0}+0.5 h,\right.\right. \\
\sigma_{\max }=\sigma_{0}-\alpha \sigma_{0}+E_{h} \varepsilon_{\max } ; \\
\sigma_{\min }=\sigma_{0}-\alpha \sigma_{0}+E_{h} \varepsilon_{\min } .
\end{gathered}
$$

\section{Problem implementation in MATLAB}

Suggested methodology was applied for two numerical experiments in MATLAB environment. In the first experiment we analyse a $0.3 \times 0.2 \mathrm{~m}$ cross-section subjected to bending moment $M=1000 \mathrm{kNm}$ and axial force $N=10000 \mathrm{kN}$. Material modulus of elasticity is $E=2100 \mathrm{MPa}$, hardening modulus $-E_{h}=210 \mathrm{MPa}$, yield stress $-\sigma_{0}=235 \mathrm{MPa}$. Numerical and graphical MATLAB results are shown in Figure 5, where red

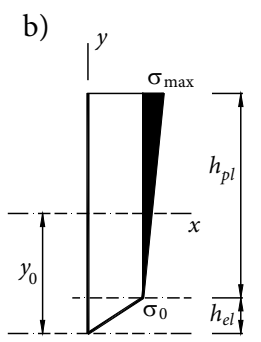

c)

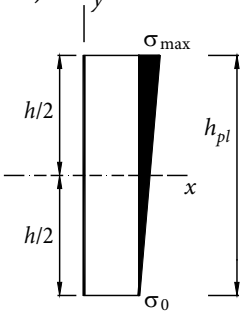

d)

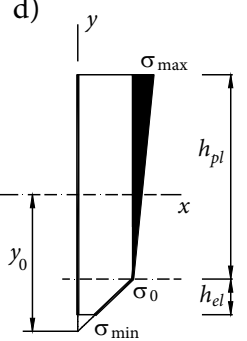

e)

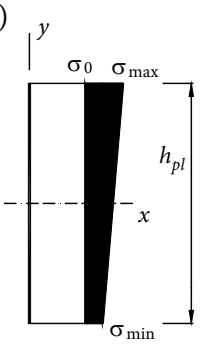

Fig. 4. Distributions of stresses in the cross-section resulted by common effect of bending moment and axial force: (a) when $N=$ $N_{\lim 2}$; (b) when $N=N_{\lim 3}$; (c) when $N=N_{\lim 4}$; (d) when $N_{\lim 3}<N<N_{\lim 4}$; (e) when $N>N_{\lim 4}$ 
Table 1. Results of the second numerical experiment

\begin{tabular}{|c|c|c|c|c|c|c|c|}
\hline Point in Fig. 6 & $N, \mathrm{kN}$ & $\sigma_{\min }, \mathrm{kPa}$ & $\sigma_{\max }, \mathrm{kPa}$ & $\kappa$ & $\varepsilon_{\min }$ & $\varepsilon_{\max }$ & Comments \\
\hline $\mathrm{A}$ & 3100 & -31666.7 & 135000 & -0.026455 & -0.001508 & 0.006429 & $1^{\text {st }}$ stress-strain state; Eq. (9) \\
\hline$N_{\lim 1}$ & 9100 & 68333.3 & 235000 & -0.026455 & 0.003254 & 0.011190 & $1^{\text {st }}$ limit axial force; Eq. (8) \\
\hline $\mathrm{B}$ & 10600 & 86682.7 & 235401.0 & -0.029907 & 0.004128 & 0.013100 & $4^{\text {th }}$ stress-strain state; Eqs. (24)-(27) \\
\hline$N_{\lim 3 \mathrm{~b}}$ & 12269.5 & 0 & 241092.6 & -0.134009 & 0 & 0.040203 & $3^{\text {rd }}$ limit axial force; Eqs. (17), (18) \\
\hline $\mathrm{C}$ & 12600 & -57908.0 & 246558.1 & -0.229956 & -0.002758 & 0.066230 & $3^{\text {rd }}$ stress-strain state; Eqs. (19)-(22) \\
\hline$N_{\lim 2 \mathrm{~b}}$ & 14322.5 & -235000 & 286223.4 & -0.887672 & -0.011190 & 0.255111 & $2^{\text {nd }}$ limit axial force; Eqs. (10), (11) \\
\hline $\mathrm{D}$ & 15100 & -235226.1 & 305178.6 & -1.192137 & -0.012267 & 0.345374 & $2^{\text {nd }}$ stress-strain state; Eqs. (12)-(16) \\
\hline$N_{\lim 2 \mathrm{c}}$ & 16426.2 & -235000 & 337618.0 & -1.703461 & -0.011190 & 0.499848 & $2^{\text {nd }}$ limit axial force; Eqs. (10), (11) \\
\hline $\mathrm{E}$ & 18100 & -82663.9 & 378328.9 & -2.325485 & -0.003936 & 0.693709 & $3^{\text {rd }}$ stress-strain state; Eqs. (19)-(22) \\
\hline$N_{\lim 3 \mathrm{c}}$ & 18542.3 & 0 & 388926.5 & -2.480580 & 0 & 0.744174 & $3^{\text {rd }}$ limit axial force; Eqs. (17), (18) \\
\hline$N_{\lim 4}$ & 19100 & 235000 & 401666.7 & -2.645503 & 0.011190 & 0.804841 & $4^{\text {th }}$ limit axial force; Eq. (23) \\
\hline $\mathrm{F}$ & 22100 & 268333.3 & 435000 & -2.645503 & 0.169921 & 0.963571 & $5^{\text {th }}$ stress-strain state; Eqs. (28)-(30) \\
\hline
\end{tabular}

the top of the cross-section (point B), meanwhile the bottom layers of the cross-section remains in the elastic state and therefore Equations (24)-(27) are used to define the stress-strain state of the section (fourth case of equilibrium). If axial force increases further, the cases of equilibrium vary in such order (Table 1): $3^{\text {rd }}$ case (point C), $2^{\text {nd }}$ case (point D), $3^{\text {rd }}$ case (point E), $4^{\text {th }}$ case and finally $5^{\text {th }}$ case (point F). As seen from the curve of $\sigma_{\min }$ variation (Fig. 6a), the stress between points $\mathrm{B}$ and $\mathrm{D}$ decreases, despite that axial force still increases. At the same time the area of plastic deformations at the top of cross-section increases very fast, meanwhile plastic deformations are zero or very small at the bottom. Such a big difference between development of plastic deformations at the top and the bottom of cross-section causes temporary decrease of $\sigma_{\text {min }}$. Normal stress at the top of the cross-section $\sigma_{\max }$ and the absolute value of curvature $\kappa$ non-linearly but constantly increases with the increase of axial force and area of total plastic deformations (Figs 6b, 7).

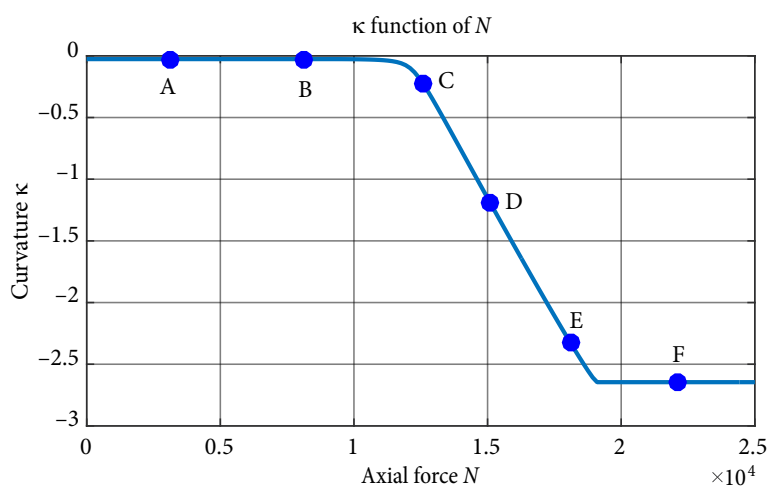

Fig. 7. Variation of the curvature of the cross-section for the second numerical example

\section{Conclusions}

- The stress-strain state of a rectangular cross-section made of linearly hardening material under combined effect of bending moment and axial force was investigated in detail. Numerical experiments demonstrate non-linear variations of stresses and strains as functions of axial force. An important observation is that a temporary decrease of normal stress at the bottom of the cross-section is possible even if axial force is constantly increasing.

- Stress-strain relation functions obtained in this paper are useful in the applications of analysis and optimization problems of linearly hardening material (e.g. steel) frame structures. These applications are under current investigation by the authors and show promising results.

- Presented derivation techniques and methods of analysis can easily be adapted and applied for other types of cross-sections.

- Described methodology can be applied for different and more complicated models of physically nonlinear materials (i.e. linear-softening or stress-strain diagrams composed of more than two linear segments).

\section{References}

Atkočiūnas, J.; Čižas, A. E. 2009. Netamprių konstrukcijų mechanika [Mechanics of inelastic structures]. Vilnius: Technika (in Lithuanian).

Byfield, M. P.; Davies, J. M.; Dhanalakshmi, M. 2005. Calculation of the strain hardening behaviour of steel structures based on mill tests, Journal of Constructional Steel Research 61(2): 133-150. http://doi:10.1016/j.jcsr.2004.08.001 
Čyras, A.; Borkowski, A.; Karkauskas, R. 2004. Theory and methods of optimization of rigid-plastic systems. Vilnius: Technika.

Davies, J. M. 2002. Second-order elastic plastic analysis of plane frames, Journal of Constructional Steel Research 58: 13151330. http://doi:10.1016/S0143-974X(02)00013-5

Dulinskas, E. J.; Zamblauskaite, R.; Zabulionis, D. 2010. An analysis of elasto-plastic bar cross-section stress-strain state in a pure bending, in Modern Building Materials, Structures and Techniques 10th International Conference, 19-21 May 2010, Vilnius, Lithuania, 599-603.

Jaras, A.; Kačianauskas R. 2001. Bimetalių dvitėjų sijų būvio analizè, ịvertinant plastinių deformacijų ịtaką [Elastic-plastic analysis of bisteel i-section beams], Statyba 7(2): 122-130. (in Lithuanian)

http://dx.doi.org/10.1080/13921525.2001.10531713

Jaras, A.; Kačianauskas, R. 2002. The investigation of load carrying capacity of elastic-plastic strain hardening bisteel isection beams, Journal of Civil Engineering and Management 8(1): 34-41. http://dx.doi.org/10.1080/13923730.2002.10531247

Juriev, A. G. 1977. Reshenije nielinejnych zadatch stroitelnoj mechaniki [Solution of non-linear problems of structural engineering]. Moskva: MISI (in Russian).

Hu, X. B.; Zhou, P. 2012. The second order elastic-plastic analysis of plane steel frame structures with semi-rigid connections, Applied Mechanics and Materials 166-169: 454-458. http://doi:10.4028/www.scientific.net/AMM.166-169.454
Kalanta, S. 2007. Taikomosios optimizacijos pagrindai [Fundamentals of applied optimization]. Vilnius: Technika (in Lithuanian).

Landesmann, A. 2010. Plastic-hinge approach for inelastic analysis of steel-concrete framed structures, Journal of Constructional Steel Research 66: 323-334.

http://doi:10.1016/j.jcsr.2009.10.014

Moore, H. 2014. MATLAB for engineers. $4^{\text {th }}$ ed. Prentice Hall.

Sawko, F. 1964. Effect of strain hardening on the elasto-plastic behavior of beams and grillages, Proceedings of the Institution of Civil Engineers 28: 489-504.

Sekulovic, M.; Nefovska-Danilovic M. 2008. Contribution to transient analysis of inelastic steel frames with semi-rigid connections, Engineering Structures 30: 976-989. http://doi:10.1016/j.engstruct.2007.06.004

Van Long, H.; Dang Hung, N. 2008a. Local buckling check according to Eurocode-3 for plastic-hinge analysis of 3-D steel frames, Engineering Structures 30(11): 3105-3113. http://doi:10.1016/j.engstruct.2008.04.002

Van Long, H.; Dang Hung, N. 2008b. Second-order plastichinge analysis of 3-D steel frames including strain hardening effects, Engineering Structures 30(12): 3505-3512. http://doi:10.1016/j.engstruct.2008.05.013

Webster, G. A.; Ellison, E. G. 1967. Iterative procedures for elastic, plastic and creep deformation of beams, Journal of Mechanical Engineering Science 9(2): 107-114. http://doi: 10.1243/JMES_JOUR_1967_009_019_02

Andrius GRIGUSEVIČIUS is Assistant lecturer at the Department of Structural Mechanics, Vilnius Gediminas Technical University. His research interests include analysis and optimization of elastic-plastic structural systems, plate on deformable foundation contact problems.

Gediminas BLAŽEVIČIUS, Dr is Assistant lecturer at the Department of Structural Mechanics, Vilnius Gediminas Technical University. His research interests include nonlinear analysis, optimization and optimal shakedown design of structural systems. 